\title{
Comprometimento Afectivo dos Membros Organizacionais: o Papel das Percepções de Justiça
}

Arménio Rego

\section{Resumo}

O estudo procura mostrar como cinco dimensões de justiça (distributiva das tarefas, distributiva das recompensas, procedimental, interpessoal e informacional) explicam o comprometimento afectivo dos professores universitários. Foi recolhida uma amostra de 309 professores oriundos de cinco instituições politécnicas e quatro universidades portuguesas. Os resultados sugerem o seguinte: (1) os professores mais afectivamente comprometidos com as suas instituições são os que denotam percepções de justiça interpessoal e procedimental mais positivas; (2) as percepções de justiça interpessoal e de distribuição das tarefas reforçam ou atenuam os efeitos de outras facetas. Os dados são discutidos à luz da pertinência do tópico para a gestão das universidades e, mais especificamente, para a qualidade no ensino superior.

Palavras-chaves: comprometimento afectivo; percepções de justiça; gestão de universidades; qualidade no ensino superior.

\section{Abstract}

The study aims at showing how five justice dimensions (task distribution, rewards distribution, procedural, interpersonal and informational) explain the affective commitment of university teachers. A sample comprising 309 teachers from five polytechnic institutions and four universities was collected. The main findings are as follow: (1) the teachers more affective committed are those having higher interpersonal and procedural justice perceptions; (2) informational and task distributive justice strength or mitigate the effects of the other justice dimensions. The findings are discussed in terms of the management of the universities and, specifically, of the quality in higher education.

Key words: affective commitment; justice perceptions; management of the universities; quality in higher education. 
INTRODUÇÃO

\section{Comprometimento dos Professores e Qualidade nas Instituições Universitárias}

O comprometimento organizacional pode ser concebido como um estado psicológico que caracteriza a ligação dos indivíduos à organização (Meyer e Allen, 1991; Allen e Meyer, 1996; Meyer, 1997). Genericamente, presume-se que as pessoas mais comprometidas têm maiores probabilidades de permanecerem na organização e de se empenharem na realização do seu trabalho e no alcance dos objectivos organizacionais.

O tópico vem ocupando desde há vários anos um lugar central nas preocupações dos investigadores que se debruçam sobre as atitudes e comportamentos dos membros organizacionais (e.g., Porter , Steers e Mowdoy, 1974; Mowday e Steers, 1979; Meyer eAllen, 1984; Allen e Meyer, 1990; Meyer, 1997; Bagrain, 2000; Cohen, 2000; Finegan, 2000). Swailes (2000, p. 199) expressou-se lapidarmente a este propósito ao enunciar que "será difícil encontrar na literatura sobre organizações um tópico que tenha atraído mais interesse do que o comprometimento”. A exuberância das pesquisas e o interesse que o tema tem suscitado nos meios científicos, académicos e organizacionais/ empresariais podem ser creditados, em grau muito considerável, à evidência de que o comprometimento pode ter implicações no absentismo, turnover, comportamentos de cidadania, satisfação e desempenho das pessoas (O’ Reilly e Chatman, 1986; Meyer et al., 1989; Konovsky e Cropanzano, 1991; Hackett, Bycio e Hausdorf, 1994; Allen e Meyer, 1996; Bolon, 1997; Meyer, 1997; MacKenzie, Podsakoff e Ahearne, 1998; Cohen, 2000; Yousef, 2000a).

A ideia subjacente é, por conseguinte, a de que o comprometimento dos indivíduos induz efeitos positivos para a eficácia das organizações em que exercem funções. Goleman (1998) expôs lapidarmente esta concepção ao gizar a seguinte linha argumentativa:

- Quando empenhadas e devotas ao seu trabalho, as pessoas estão dispostas a fazer sacrifícios, a suportar condições de trabalho altamente exigentes, isto é: a actuarem como patriotas das suas organizações.

- As pessoas empenhadas representam modelos de actuação que os restantes membros podem imitar. "Tal como seixos numa piscina [...] elas lançam ondas de bons sentimentos a toda a organização” (Goleman, 1998, p. 128). 
. A entrega à organização tem a sua génese em laços emocionais, gerando “confiança, apego e lealdade”, assim como actos de boa cidadania organizacional. Tais laços dependem, em medida considerável, do grau em que as pessoas sentem que são tratadas com justiça e respeito.

O presente artigo incide sobre o comprometimento dos professores universitários na sua instituição, e sobre os efeitos que as percepções de justiça sobre ele podem exercer. É pertinente que o tópico seja projectado sobre este tipo específico de organizações porque a fertilidade dos estudos em meios organizacionais convencionais não tem correspondência no seio das pesquisas com docentes do ensino superior. Num tempo em que a qualidade neste nível de ensino preenche um considerável espaço entre as preocupações dos investigadores e governantes das instituições de ensino superior (e.g., Sallis, 1993; Ellington e Ross, 1994; Feigenbaum, 1994; Rubach, 1994; Bailey e Bennett, 1996; Hansen e Jackson, 1996; Rowley, 1996; Horsburgh, 1999; Montano e Utter, 1999), torna-se imperativo levar a cabo estudos que permitam explicar as razões pelas quais os professores se sentem comprometidos com as suas universidades. Se os gestores/governantes deste tipo específico de organização aprofundarem o conhecimento dessas razões, é presumível que fiquem mais habilitados a fomentar o mencionado comprometimento dos seus professores. Uma reflexão cuidada sobre alguma literatura que tem vindo a ser publicada sustenta a pertinência do tema:

. Como membros organizacionais que são, não parece haver razões para presumir que os professores do ensino superior tenham um padrão comportamental distinto do da generalidade das pessoas. O próprio Goleman (1998) fez, aliás, menção a trabalho empírico realizado com amostras inclusivas de professores.

- Se os indivíduos em geral tendem a adoptar mais comportamentos de cidadania organizacional quando se sentem comprometidos com as suas organizações, é verossímil que os professores universitários mais comprometidos com a sua instituição propenderão para adoptar mais comportamentos de cidadania docente - CIDOCE (Rego, 2000a, 2000b, 2000c; Rego e Sousa, 2000; Rego e Reis, 2001).

. O estudo dos CIDOCE adquire importância acrescida porque os dados empíricos revelam que eles são fortemente valorizados por docentes, estudantes e diplomados, e que explicam a motivação profissional, a autoconfiança e o desempenho académico dos estudantes (Rego, 2000a, 2000b, 2000c; Rego e Sousa, 2000; Rego e Reis, 2001).

. Estes dados fazem jus à ideia segundo a qual a gestão da qualidade do ensino superior passa, em grau considerável, pela qualidade do processo ensinoaprendizagem (e.g., Ellington e Ross, 1994; Schargel, 1994; Bailey e Bennett, 
1996; Hansen e Jackson, 1996; Rowley, 1996; Yorke, 1997; Horsburgh, 1999). Helms e Key (1994, p. 97) enunciaram eloquentemente essa tese afirmando que "não há lugar algum onde os resultados positivos da gestão da qualidade total sejam mais necessários do que [...] na sala de aula”.

. A este propósito, Hansen e Jackson (1996, p. 211-212) lançaram um desafio que importa enfrentar: "apesar do extenso discurso sobre a qualidade, a actividade nuclear das universidades - a docência - permanece em grande medida intacta”.

- Parece então crucial estudar as motivações subjacentes aos actores docentes para melhor se compreender o que os induz a desenvolver laços psicológicos de comprometimento com as suas instituições.

A literatura produzida no âmbito da psicologia industrial/organizacional sugere, de modo bastante enfático, que o comprometimento dos indivíduos pode ser explicado, em medida significativa, pelas suas percepções de justiça (e.g., Kim e Mauborgne, 1991, 1996, 1997; McFarlin e Sweeney, 1992; Moorman, Niehoff e Organ, 1993; Sweeney e McFarlin, 1993; Tansky, 1993; Mossholder, Kemery e Wesolowski, 1998; Naumann et al., 1998). Será que o mesmo tende a ocorrer com os professores do ensino superior? A resposta a esta questão merece especial atenção. Efectivamente, se os professores detentores de sentimentos de justiça mais positivos tendem a denotar mais elevado comprometimento afectivo (amor à camisola), mais CIDOCE, mais elevados níveis de satisfação, menor absentismo, superior desempenho ... então cabe aos decisores/governantes das universidades (nos diversos níveis decisórios, sejam eles micro ou macro) actuarem com o fito de promoverem a melhoria dessas percepções.

O presente artigo visa, precisamente, a mostrar como tendem a reagir os professores do ensino superior, em matéria de comprometimento organizacional afectivo, perante as percepções de justiça que projectam sobre vários planos da vida académica: (1) distribuição do serviço docente e outras tarefas pedagógicas, científicas e administrativas; (2) distribuição de recompensas; (3) procedimentos decisórios e atinentes às promoções; (4) grau de dignidade e respeito com que os superiores tratam os professores; (5) grau em que os superiores explicam as decisões aos professores e ouvem os seus pontos de vista antes de decidirem.

Os resultados do estudo aqui expostos lançam luz adicional sobre o modo como os membros organizacionais reagem ao modo como se sentem (in)justiçados. Ao sugerir que a classe específica dos professores universitários não foge à tendência que tem vindo a ser gizada em meios organizacionais/industriais, o estudo corrobora o que inúmeros autores têm vindo a advogar (Rawls, 1971; Greenberg, 1990; Kim e Mauborgne, 1997; Goleman, 1998; Bloom, 1999; Williams, 1999): a justiça representa um elemento indissociável da vida humana e, a fortiori, da vida 
organizacional, podendo influenciar desempenhos individuais e organizacionais, assim como o grau de satisfação das pessoas.

\section{A Multidimensionalidade do Comprometimento Organizacional}

Embora seja consensual que o comprometimento é um constructo multidimensional, não há convergência acerca das referidas dimensões. A tese mais comum propugna pela tripartição (Allen e Meyer, 1990; Meyer e Allen, 1991; Meyer, 1997; Pavuls, 2000): comprometimento afectivo, normativo e instrumental ou calculativo (vide Quadro 1). Todavia, alguns investigadores (e.g., McGee e Ford, 1987; Meyer e Allen, 1991; Hackett, Bycio e Hausdorf, 1994; Allen e Meyer, 1996; Iverson e Buttigieg, 1999) aventam a possibilidade/pertinência de o comprometimento instrumental/ calculativo ser particionado em duas vertentes: (1) o indivíduo mantém-se ligado à organização porque sente que não tem alternativas de emprego; (2) essa ligação assenta na ideia de que os custos pessoais inerentes à saída são elevados.

\section{Quadro 1: As Três Componentes mais Comuns do Comprometimento Organizacional}

\begin{tabular}{llll}
\hline Categorias & Caracterização & $\begin{array}{l}\text { A pessoa permanece } \\
\text { na organização } \\
\text { porque ... }\end{array}$ & $\begin{array}{l}\text { Estado } \\
\text { psicológico }\end{array}$ \\
\hline Afectivo & $\begin{array}{l}\text { Grau em que o colaborador se sente } \\
\text { emocionalmente ligado, identificado e envolvido } \\
\text { na organização. }\end{array}$ & $\begin{array}{l}\text {... sente que quer } \\
\text { permanecer. }\end{array}$ & Desejo \\
Normativo & $\begin{array}{l}\text { Grau em que o colaborador possui um sentido da } \\
\text { obrigação (ou dever moral) de permanecer na } \\
\text { organização. }\end{array}$ & $\begin{array}{l}\text {... sente que deve } \\
\text { permanecer. }\end{array}$ & Necessidade \\
$\begin{array}{l}\text { Instrumental } \\
\text { (ou }\end{array}$ & $\begin{array}{l}\text { Grau em que o colaborador se mantém ligado à } \\
\text { organização devido ao reconhecimento dos custos } \\
\text { associados com a sua saída da mesma. Este } \\
\text { reconhecimento pode advir da ausência de } \\
\text { alternativas de emprego, ou do sentimento de que } \\
\text { os sacrifícios pessoais gerados pela saída serão } \\
\text { elevados. }\end{array}$ & $\begin{array}{l}\text { necessidade de } \\
\text { permanecer. }\end{array}$ & \\
\hline
\end{tabular}

Fonte: McGee e Ford (1987), Allen e Meyer (1990), Meyer e Allen (1991), Hackett, Bycio e Hausdorf (1994), Meyer (1997) e Iverson e Buttigieg (1999).

A maior dificuldade em optar ou não pelo tetra-modelo reside no facto de ele se ajustar melhor aos dados, embora as duas dimensões calculativas se interrelacionem fortemente e com outras variáveis (Hackett, Bycio e Hausdorf, 1994). Decifra-se maior consenso (teórico e empírico) em torno da necessidade de discernir entre as facetas afectiva, normativa e calculativa. Na base desta convergência está a evidência assente em três pilares: 
. Os modelos tri-factoriais ajustam-se satisfatoriamente aos dados (Allen e Meyer, 1990, 1996; Meyer et al., 1993; Hackett, Bycio e Hausdorf, 1994).

. Os antecedentes de cada faceta são distintos (Allen e Meyer, 1990, 1996; Meyer e Allen, 1991; Hackett, Bycio e Hausdorf, 1994; Meyer, 1997). Por exemplo, as percepções positivas de justiça promovem o comprometimento afectivo (e, em menor grau, o normativo), mas não o calculativo. Algumas variáveis como o feedback, a dificuldade dos objectivos e o desafio inerente ao cargo fomentam o comprometimento normativo e, especialmente o afectivo, mas relacionam-se negativamente com o calculativo.

- As conseqüências de cada faceta são igualmente distintas (Allen e Meyer, 1996; Meyer, 1997; Iverson e Buttigieg, 1999). Por exemplo, o comprometimento afectivo (e, menos intensivamente, o normativo) induz menores intenções de abandonar a organização, menos abandonos efectivos e mais baixos índices de absentismo, mas isso não é tão claro no que concerne ao calculativo. Ainda ilustrando, parece haver razões para presumir que a vertente afectiva é a que mais fortemente se relaciona com o desempenho. Em suma: a vontade dos indivíduos de contribuírem para os objectivos organizacionais parece ser influenciada pela natureza do laço psicológico que os liga à organização. É mais provável que exerçam elevados esforços de desempenho quando desejam pertencer à organização, do que quando se sentem obrigados ou necessidade de nela se inserirem.

A investigação cujos resultados serão aqui expostos debruça-se sobre o comprometimento afectivo dos professores do ensino superior. Os dados teóricos e empíricos existentes a respeito dos membros organizacionais convencionais (e.g., O’Reilley e Chatman, 1986; Meyer e Allen, 1991; Becker, 1992; Cordery et al., 1993; Moorman, Niehoff e Organ, 1993; Schaubroeck, May e Brown, 1994; Iverson, 1996; Meyer, 1997; McKenzie, Podsakoff e Ahearne, 1998; Caetano e Vala, 1999; Iverson e Buttigieg, 1999; Yousef, 2000a, 2000b) sugerem que as pessoas mais comprometidas afectivamente denotam menos vontade/intenção de abandonarem a organização, maior pontualidade, menores índices de absentismo, maior grau de aceitação das mudanças organizacionais, e mais elevados índices de comportamentos de cidadania organizacional. Será que os docentes do ensino superior mais afectivamente comprometidos com a sua instituição denotam atitudes e comportamentos similares?

A resposta a esta questão é fulcral, pois é verossímil admitir que tais atitudes e comportamentos possam actuar positivamente sobre a qualidade do ensino superior e, especificamente, a qualidade do processo ensino-aprendizagem (e.g., Ellington e Ross, 1994; Helms e Key, 1994; Schargel, 1994; Bailey e Bennett, 1996; Hansen e Jackson, 1996; Rowley, 1996; Yorke, 1997; Horsburgh, 1999). No que concerne, 
especificamente, aos CIDOCE, existe aliás diversa evidência empírica sugerindo que eles são fortemente valorizados pelos estudantes e explicam significativamente a sua motivação, auto-confiança e desempenho académico (Rego, 2000a, 2000b, 2000c; Rego e Sousa, 2000; Rego e Reis, 2001). Por conseguinte, a questãochave pode, muito simplesmente, ser enunciada deste modo: se é provável que os professores mais comprometidos afectivamente com a sua instituição desenvolvem atitudes e comportamentos positivos para a qualidade da vida académica, como podemos desenvolver-lhes esse comprometimento?

\section{A Justiça como Antecedente do Comprometimento Organizacional}

A resposta a esta interrogação pode ser escrutinada numa grande diversidade de estudos (e.g., Steers e Porter, 1990; Meyer e Allen, 1991; McFarlin e Sweeney, 1992; Moorman, Niehoff e Organ, 1993; Sweeney e McFarlin, 1993, 1997; Meyer, 1997; Pond et al., 1997; Schaubroeck, May e Brown, 1997; McKenzie, Podsakoff e Ahearne, 1998; Mossholder, Kemery e Wesolowski, 1998; Iverson e Buttigieg, 1999). Assim, e ilustrando, é provável que as pessoas que desenvolvem mais facilmente o comprometimento afectivo sejam as mais satisfeitas, as que exercem tarefas enriquecidas e não-rotineiras, têm oportunidades efectivas de promoção na carreira, percepcionam o apoio dos colegas, perfilham valores mais congruentes com os da organização, podem participar na tomada de decisão, vêem cumpridas as expectativas anteriores ao ingresso na organização, percepcionam que a organização os valoriza e cuida do seu bem-estar, e têm percepções positivas de justiça (especialmente interaccional e/ou procedimental).

O presente trabalho debruçar-se-á, especificamente, sobre as percepções de justiça. O seu objectivo é o de testar se, de facto, os professores com percepções mais positivas denotam níveis superiores de comprometimento afectivo com a sua instituição. Para que se compreenda o tópico, é fundamental esclarecer que as investigações em meios organizacionais convencionais tendem a sugerir a existência de três dimensões de justiça:

. A justiça distributiva (e.g., Adams, 1965) foi a que primeiramente suscitou a atenção dos cientistas organizacionais. Focaliza-se no conteúdo, isto é, na justiça dos fins alcançados ou obtidos (por exemplo, salários, classificações obtidas nas avaliações de desempenho, sanções disciplinares, lucros distribuídos aos trabalhadores).

. A justiça procedimental (e.g., Thibaut e Walker, 1975, 1978; Lind e Tyler, 1988) focaliza-se no processo, ou seja, na justiça dos meios usados para alcançar tais fins. 
. A justiça interaccional (e.g., Bies e Moag, 1986; Tyler e Bies, 1990; Greenberg, 1993a; Rego, 2000g) reflecte a qualidade da interacção com os decisores (por exemplo, o gestor age com dignidade e respeito? oferece justificações aos indivíduos afectados pelas decisões?).

Pode ilustrar-se o triângulo com o exemplo de uma sanção disciplinar: a sanção propriamente dita (justiça distributiva), o processo que a determina (procedimental) e o modo como o superior a transmite, explica e justifica ao colaborador (interaccional). As percepções positivas em certa(s) faceta(s) podem coabitar com percepções negativa(s) noutra(s) faceta(s). Por exemplo, um indivíduo pode considerar que a sanção e o processo são justos, mas revelar percepções de baixa justiça (interaccional) devido à rudeza com que o superior o aborda.

\section{Quadro 2: Dimensões de Justiça Detectáveis na Literatura Organizacional}

\begin{tabular}{ll}
\hline Dimensões/facetas & Caracterização \\
\hline Justiça distributiva & $\begin{array}{l}\text { Focaliza-se no conteúdo, isto é, na justiça dos fins alcançados ou obtidos. } \\
\text { Respeita, por exemplo, aos salários, classificações obtidas pelas pessoas } \\
\text { nas avaliações de desempenho, sanções disciplinares, promoções, } \\
\text { aceitação/rejeição de candidatos, resultados dos testes de detecção de } \\
\text { consumo de droga, fatia orçamental atribuída às unidades organizacionais, } \\
\text { lucros distribuídos aos trabalhadores. } \\
\text { Focaliza-se no processo, ou seja, na justiça dos meios usados para } \\
\text { alcançar tais fins. Concerne, por exemplo, aos procedimentos usados nos } \\
\text { acréscimos salariais, processos disciplinares, sistemas de avaliação de } \\
\text { desempenho, processos de recrutamento e selecção. } \\
\text { Justiça interaccional } \\
\text { social/interpessoal }\end{array} \quad \begin{array}{l}\text { Incide sobre o grau em que o superior adopta um tratamento digno e } \\
\text { respeitador para com os seus colaboradores. } \\
\text { Justiça interaccional } \\
\text { informacional }\end{array}$ \\
\hline
\end{tabular}

Fonte: Adams (1965), Thibaut e Walker (1975, 1978), Bies e Moag (1986), Lind e Tyler (1988), Greenberg (1993a), Cropanzano e Greenberg (1997) e Rego (2000d, 2000e, 2000f).

Alguns dados teóricos e empíricos (e.g., Greenberg e McCarty, 1990; Greenberg, 1993a; Konovsky, 2000; Rego, 2000d, 2000e, 2000f) sugerem, ainda, que se distingam, no âmbito da justiça interaccional, as facetas social/interpessoal e informacional (vide Quadro 2).

Há, no entanto, razões para presumir que a dimensionalização não é independente dos contextos em que os indivíduos actuam (Greenberg, 19993b). Num estudo realizado com 208 docentes de 3 universidades e 2 instituições politécnicas portuguesas, Rego (2001a) conferiu suporte empírico a esta presunção. Com efeito, obteve uma estrutura factorial em que a vertente distributiva surgiu dividida em duas facetas: distribuição das tarefas e das recompensas. Quando testou o 
potencial preditivo das quatro dimensões de justiça para uma medida de comprometimento afectivo, Rego (2001a) verificou que a variância explicada se cifrava em cerca de $30 \%$, sendo que apenas a justiça interaccional e procedimental denotavam valor explicativo significativo (para $\mathrm{p}<0.05$ ).

Sucede que o investigador detectou um dado empírico adicional relevante. Quando dividiu os itens da faceta interaccional de acordo com o seu conteúdo semântico, criando assim as vertentes social/interpessoal e informacional, Rego (2001a) notou o seguinte: (1) a variância explicada do comprometimento beneficiava de um incremento de 2 pontos percentuais; (2) de entre as duas vertentes, apenas a interpessoal manteve potencial explicativo significativo. A pertinência da partição da faceta interaccional em duas vertentes reemergiu em estudo confirmatório posterior (Rego, 2001b), pois a estrutura penta-factorial denotou índices de ajustamento superiores ao tetra-factorial.

A presente investigação representa um passo adicional na compreensão das razões que induzem os professores do ensino superior a mais elevados índices de comprometimento afectivo. Na senda da evidência empírica exibida por Rego (2001a), a hipótese subjacente presume que as facetas procedimental e interaccional denotam maior potencial explicativo do comprometimento afectivo do que as vertentes distributivas. A premissa baseia-se na tese dos efeitos diferenciais (McFarlin e Swweney, 1992; Sweeney e McFarlin, 1993), vastamente enunciada no âmbito dos estudos organizacionais. Nos seus termos, a justiça procedimental/interaccional e distributiva têm diferentes conseqüências: a procedimental está associada com as avaliações do sistema organizacional (reflectidas em variáveis como a lealdade à organização, o comprometimento organizacional e a confiança na gestão), enquanto a distributiva se associa preferencialmente com a satisfação com os resultados específicos em questão ou os resultados de determinada decisão. Esta noção recebeu apoio empírico em vários estudos (e.g., Folger e Konovsky, 1989; Kim e Mauborgne, 1991, 1996; McFarlin e Sweeney, 1992; Sweeney e McFarlin, 1993; Lee e Farh, 1999), sendo escassa a evidência empírica que a não corrobora (e.g., Hartman, Yrle e Galle, 1998).

O estudo testará, ainda, se as diferentes vertentes da justiça interagem para produzir resultados. Na verdade, e ilustrando, embora a justiça distributiva possa não explicar independentemente o comprometimento afectivo, pode suceder que reforce ou atenue os efeitos da (in)justiça procedimental/interaccional. Diversa evidência teórica e empírica sugere que tal pode ocorrer (Cropanzano e Folger, 1991; Brockner e Siegel, 1996; Brockner e Wiesenfeld, 1996; Grienberger, Rutte e Knippenberg, 1997; Skarlicki e Folger, 1997). A argumentária típica pode ser assim gizada:

. Se uma pessoa recebe resultados justos, a relevância dos procedimentos e das 
interacções para as suas reaç̧ões é reduzida. Mais precisamente, não serão os procedimentos e/ou interacções injustas a induzi-lo a retaliar e a baixar o seu comprometimento.

. Se os resultados recebidos são injustos, os procedimentos/interacções justas podem inibi-lo de agir contra a organização. Mas se a pessoa assiste a uma combinação de resultados injustos com procedimentos/interacções injustas, as suas reacções negativas tenderão a ser vigorosas (Cropanzano e Folger, 1991).

. Depreende-se claramente destes enunciados que cada dimensão se substitui, pelo menos parcialmente, à outra na produção dos efeitos: a justiça procedimental/interaccional exerce maiores impactos quando o resultado é injusto ou desfavorável, e a distributiva exerce maiores efeitos quando os procedimentos são injustos.

\section{Metodologia}

Foi inquirida uma amostra constituída por 309 professores do ensino superior, oriundos de 5 instituições politécnicas e 4 universidades portuguesas. Distribuíamse por todas as categorias da carreira docente, sendo $47 \%$ doutorados e $40 \%$ não-doutorados (13\% não-respostas). A abordagem foi feita a 1.300 professores, através de carta depositada na sua caixa de correio. A taxa de resposta foi, pois, de $24 \%$. A cada inquirido foi distribuído um questionário composto de duas partes.

- A primeira continha 17 descritores atinentes às suas percepções de justiça. Estes itens fazem parte de um questionário desenvolvido e validado por Rego (2001a, 2001b), provindo da revisão de literatura e da análise de conteúdo de entrevistas semi-estruturadas realizadas a professores do ensino superior. As análises factoriais e o estudo do poder preditivo das percepções de justiça para o comprometimento afectivo sugeriram que o modelo mais apropriado contém 5 dimensões de justiça: distributiva das recompensas, distributiva das tarefas, procedimental, interpessoal e informacional.

- A segunda parte albergava três itens respeitantes ao comprometimento afectivo. Foram recolhidos na literatura (Porter, Steers e Mowday, 1974; Allen e Meyer, 1990) e adaptados.

- Em ambos os casos, os inquiridos foram convidados a responder através de escalas tipo Likert contendo 6 pontos (1: discordo completamente; 6: concordo completamente). 
Os dados foram submetidos a uma análise factorial confirmatória (com o recurso ao LISREL, e com base no método da máxima verossimilhança), à luz do modelo de seis factores: cinco de justiça e um de comprometimento. Os índices de ajustamento revelaram-se satisfatórios. Foram então computadas as cotações de cada indivíduo nas seis variáveis subjacentes. O método de cálculo foi a média aritmética das cotações nos itens constituintes de cada dimensão. Foram, então, executadas regressões para o comprometimento afectivo. Finalmente, foi levada a cabo uma análise de clusters (distância: euclidiana ao quadrado; método: vizinho mais afastado), e uma análise de variância, tendo sido adoptada a seguinte estratégia de pesquisa:

. Os indivíduos foram agrupados de acordo com o seu comprometimento afectivo.

. Foi seleccionada uma solução de seis grupos.

. Foram estabelecidas comparações de médias entre os grupos, para as variáveis de justiça e comprometimento.

\section{Resultados}

A Tabela 1 expõe a estrutura hexa-factorial testada, os índices de ajustamento do modelo e os Alphas de Cronbach para cada variável. Os índices de ajustamento satisfazem os requisitos habitualmente preconizados (Joreskog e Sorbom, 1993; Byrne, 1998). Todos os Lambdas se situam num patamar que pode ser considerado elevado. Os coeficientes de consistência interna são sempre superiores ao mínimo de 0.70 sugerido por Nunnally (1978).

A Tabela 2 expõe as médias, desvios-padrão e correlações entre variáveis. As correlações entre as várias dimensões de justiça são sempre significativas, e especialmente elevadas no que concerne às vertentes interpessoal, informacional e procedimental. As correlações entre a justiça e o comprometimento são também especialmente elevadas para as mesmas três facetas. Frise-se, desde já, que as correlações entre as dimensões de justiça erigem uma dificuldade metodológica e psicométrica: a sua (não) independência. 


\section{Tabela 1: Análise Factorial Confirmatória (Solução Completamente Estandardizada)}

\section{Justiça interpessoal}

1. Os meus superiores mostram interesse genuíno em serem justos comigo.

2. Os meus superiores lidam comigo de modo honesto e ético.

3. Os meus superiores são completamente francos e sinceros comigo.

4. Antes de decidirem sobre assuntos que me dizem respeito, os meus superiores procuram ouvir os meus pontos de vista.

5. Quando tomam decisões sobre o meu trabalho, os meus superiores dão-me explicações com sentido para mim.

6. Quando tomam decisões sobre o meu trabalho, os meus superiores discutem comigo as implicações dessas decisões.

\section{Justiça procedimental}

7. Os critérios usados para as promoções são justos.

8. Os procedimentos da minha instituição asseguram que as decisões são tomadas sem favorecimentos pessoais

9. As decisões são tomadas de modo consistente para todos os professores.

\section{Justiça distributiva das recompensas}

10. Tendo em conta a minha experiência, considero que as recompensas que recebo são justas.

11. Considerando as minhas responsabilidades, as recompensas que recebo são justas.

12. Considerando o stress e pressões da minha actividade profissional, as recompensas que recebo são justas.

13. Tendo em conta a correcção com que faço o meu trabalho, considero que as recompensas que recebo são justas.

14. Considerando o meu esforço, as recompensas que recebo são justas.

15. O serviço docente que me tem sido distribuído é justo.

16. As tarefas que me são atribuídas são justas.

17. Tendo em conta as condições de trabalho que me são facultadas, considero injustas as tarefas que me são exigidas ${ }^{(*)}$.

\section{Comprometimento afectivo}

18. Sinto muito orgulho em fazer parte desta instituição.

19. Sinto-me parte da família desta instituição.

20. A minha instituição tem um grande significado pessoal para mim.

Indices de ajustamento

Qui-quadrado/Graus de liberdade 0.85

$\begin{array}{lr}\text { Root mean square error of approximation } & 0.047\end{array}$

$\begin{array}{lr}\text { Goodness of fit index } & 0.92\end{array}$

$\begin{array}{lr}\text { Adjusted goodness of fit index } & 0.89\end{array}$

$\begin{array}{ll}\text { Comparative fit index } & 0.97\end{array}$

$\begin{array}{lr}\text { Incremental fit index } & 0.97\end{array}$

Relative fit index

${ }^{(*)}$ A cotação neste item foi invertida.

Entre parêntesis, a negrito: alphas de Cronbach. 
Tabela 2: Médias, Desvios-Padrão e Correlações

\begin{tabular}{lccccccc}
\hline & Médias & DP & 1 & 2 & 3 & 4 & 5 \\
\hline 1. Justiça interpessoal & 4.1 & 1.1 & - & & & & \\
2. Justiça informacional & 3.9 & 1.2 & 0.83 & - & & & \\
3. Justiça procedimental & 3.3 & 1.1 & 0.65 & 0.58 & - & & \\
4. J. distr. das recompensas & 3.5 & 1.3 & 0.31 & 0.31 & 0.46 & - & \\
5. J. distr. das tarefas & 4.5 & 1.1 & 0.46 & 0.44 & 0.44 & 0.44 & - \\
6. Comprometimento & 4.3 & 1.3 & 0.55 & 0.49 & 0.49 & 0.29 & 0.32 \\
\hline
\end{tabular}

Todos os coeficientes são significativos para $\mathrm{p}<0.001$.

A Tabela 3 exibe os resultados das regressões. Aponta o poder explicativo das percepções de justiça para o comprometimento. Mostra que apenas as dimensões interpessoal e procedimental (com prevalência da primeira) denotam poder explicativo, quer os docentes exerçam actividade em universidades ou instituições politécnicas. A variância explicada cifra-se em 33\% para a amostra global, sendo superior para a subamostra politécnica (46\%).

\section{Tabela 3: Regressões para o Comprometimento Afectivo}

\begin{tabular}{lccc}
\hline & $\begin{array}{c}\text { Amostra global } \\
(\mathrm{n}=309)\end{array}$ & $\begin{array}{c}\text { Politécnico } \\
(\mathrm{n}=68)\end{array}$ & $\begin{array}{c}\text { Universidade } \\
(\mathrm{n}=241)\end{array}$ \\
\hline Justiça interpessoal & $0.32^{* * *}$ & $0.43^{*}$ & $0.26^{*}$ \\
Justiça informacional & 0.081 & -0.11 & 0.14 \\
Justiça procedimental & $0.20^{* *}$ & 0.23 & $0.19 *$ \\
J. distr. das recompensas & 0.07 & 0.13 & 0.04 \\
J. distr. das tarefas & 0.03 & 0.07 & 0.02 \\
$\mathrm{~F}$ & $31.26^{* * *}$ & $12.20^{* * *}$ & $20.79 * * *$ \\
$\mathrm{R}^{2}$ ajustado & $33 \%$ & $46 \%$ & $29 \%$ \\
\hline
\end{tabular}

$* \mathrm{p}<0.05 \quad * * \mathrm{p}<0.01 \quad * * * \mathrm{p}<0.001$

Esta evidência que confere predominância ao poder explicativo das vertentes interpessoal e procedimental obscurece, todavia, a filigrana empírica que, olhada mais minuciosamente, sugere que outras dimensões ajudam a explicar o comprometimento em determinadas circunstâncias. Com efeito, após a execução de várias regressões para dois patamares (cotações inferiores a 3.5 versus superiores a 3.5) de cada dimensão, constatou-se o seguinte: 
. A justiça informacional expressa valor preditivo quando os indivíduos denotam percepções de justiça interpessoal baixas.

- O poder explicativo da justiça interpessoal é superior quando as percepções de justiça distributiva das recompensas são baixas.

- A justiça distributiva das tarefas explica o comprometimento quando a justiça informacional é fraca. O mesmo sucede quando a justiça procedimental é fraca.

Numa tentativa de tornar mais inteligíveis os dados, calcularam-se as médias de comprometimento para diferentes combinações de percepções de justiça. As Figuras 1-3 reflectem graficamente essa evidência. Sucintamente, as imagens denotadas são as seguintes:

. Os níveis de comprometimento são especialmente baixos quando se cruzam baixas percepções de justiça em duas dimensões.

. As justiças interpessoal e informacional são intersubstitutivas (vide Figura 1). Dito de outro modo, o decréscimo de justiça informacional gera menor comprometimento quando a justiça interpessoal é fraca, mas não quando é mais vincada. Similarmente, o decréscimo de justiça interpessoal gera menor comprometimento quando a justiça informacional é fraca, mas não quando é mais vincada.

. O decréscimo nas percepções de justiça informacional gera menor comprometimento quando a justiça distributiva das tarefas é fraca, mas isso não é tão claro quando as distribuições de tarefas são consideradas justas. Complementarmente, os decréscimos de justiça distributiva das tarefas prejudicam o comprometimento quando a justiça informacional é fraca, mas não quando é mais vincada (vide Figura 2).

- O decréscimo nas percepções de justiça procedimental suscitam menor comprometimento quando a justiça distributiva das tarefas é fraca, mas isso não é tão vincado quando as distribuições de tarefas são consideradas justas. Concomitantemente, os decréscimos de justiça distributiva das tarefas prejudicam o comprometimento quando a justiça procedimental é fraca, mas não quando esta é positiva (vide Figura 3). 


\section{Figuras 1-3: O Comprometimento Afectivo em Diferentes} Combinações de Percepções de Justiça
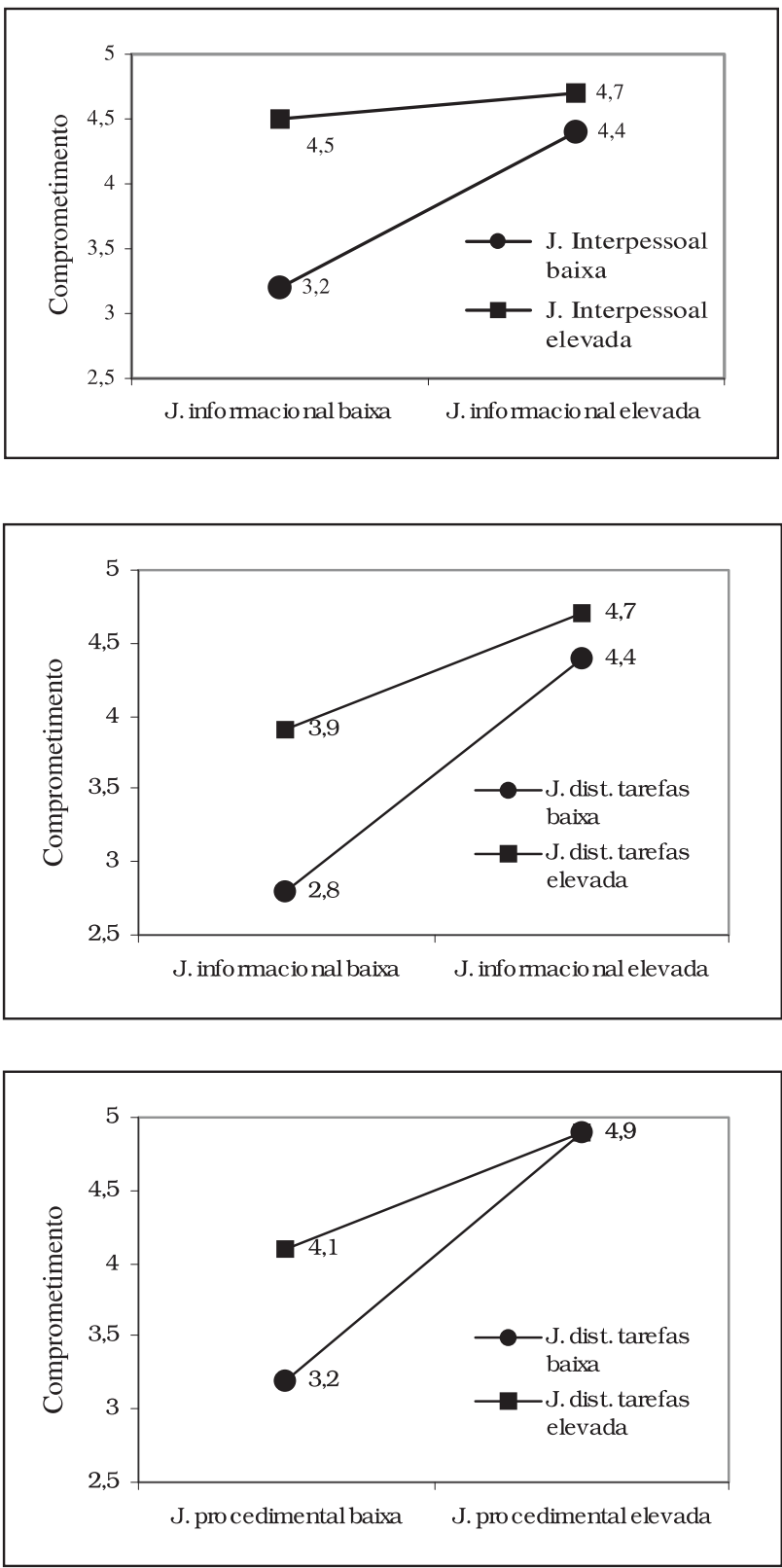
Num enunciado simples, os dados podem ser assim resumidos: (1) a fraca justiça informacional reforça os efeitos negativos da fraca justiça interpessoal, e vice-versa; (2) a fraca justiça distributiva das tarefas reforça os efeitos negativos da fraca justiça informacional, e vice-versa; (3) a fraca justiça distributiva das tarefas reforça os efeitos negativos da fraca justiça procedimental, e vice-versa; (4) as pessoas atenuam as suas reacções negativas à fraca justiça interpessoal se percepcionarem elevada justiça informacional; (5) quando as percepções de justiça distributiva das tarefas são fracas, as pessoas inibem-se de reagir negativamente se denotarem percepções de elevada justiça procedimental ou informacional.

Finalmente, a Tabela 4 expõe a caracterização dos grupos emergentes da análise de clusters. A tendência que mais transparece é a seguinte: os indivíduos mais comprometidos afectivamente com a sua instituição são os que denotam percepções de justiça mais positivas, sendo que isso é mais vincado para as vertentes interpessoal, informacional e procedimental.

Tabela 4: Agrupamentos de Indivíduos e sua Caracterização

\begin{tabular}{|c|c|c|c|c|c|c|c|}
\hline & $\begin{array}{c}\text { Grupo } 1 \\
(\mathrm{n}=14)\end{array}$ & $\begin{array}{c}\text { Grupo } 2 \\
(\mathrm{n}=10)\end{array}$ & $\begin{array}{c}\text { Grupo } 3 \\
(\mathrm{n}=34)\end{array}$ & $\begin{array}{c}\text { Grupo } 4 \\
(\mathrm{n}=95)\end{array}$ & $\begin{array}{c}\text { Grupo } 5 \\
(\mathrm{n}=94)\end{array}$ & $\begin{array}{c}\text { Grupo } 6 \\
(\mathrm{n}=60)\end{array}$ & $\begin{array}{c}\text { Quantidade } \\
\text { de pares } \\
\text { de grupos } \\
\text { diferentes }\end{array}$ \\
\hline \multirow[t]{2}{*}{ Comprometimento afectivo } & 1.2 & 1.9 & 2.8 & 4.0 & 5.0 & 5.8 & 16 (todos) \\
\hline & \multicolumn{3}{|c|}{$\begin{array}{l}\text { Afectivamente } \\
\text { ausentes }\end{array}$} & & \multicolumn{2}{|c|}{$\begin{array}{l}\text { Completamente } \\
\text { comprometidos }\end{array}$} & \\
\hline Justiça interpessoal & 2.9 & 2.9 & 3.0 & 4.0 & 4.5 & 4.9 & 11 \\
\hline Justiça informacional & 2.7 & 2.9 & 2.8 & 3.8 & 4.2 & 4.5 & 11 \\
\hline Justiça procedimental & 2.2 & 2.4 & 2.3 & 3.2 & 3.5 & 4.0 & 10 \\
\hline $\begin{array}{l}\text { Justiça na dist. das } \\
\text { recompensas }\end{array}$ & 2.4 & 3.0 & 3.0 & 3.2 & 3.8 & 3.9 & 3 \\
\hline Justiça na dist. das tarefas & 4.1 & 3.7 & 3.9 & 4.5 & 4.7 & 5.1 & 5 \\
\hline
\end{tabular}

*Teste Scheffé $(\mathrm{p}<0.05)$.

\section{Discussão e AnÁlise}

O elemento empírico central da pesquisa sugere que os professores são mais afectivamente comprometidos com a sua instituição quando denotam percepções de justiça positivas. Pode presumir-se que tal sucede devido a uma lógica de troca social (Blau, 1964; Adams, 1965; Meyer, 1997) ou de reciprocidade (Gouldner, 1960): (1) as pessoas reagem reciprocamente para com as pessoas/ 
entidades que as beneficiam; (2) pelo facto de receberem acções positivas das suas instituições, as pessoas experienciam um sentimento de obrigação/dever, em função do qual procuram responder reciprocamente.

Esta tendência geral não pode, contudo, obscurecer o facto de que apenas as vertentes interaccional (mais especificamente a interpessoal) e procedimental explicam independentemente o comprometimento. O resultado converge com o modelo dos efeitos diferenciais (Lind e Tyler, 1988; McFarlin e Swweney, 1992; Sweeney e McFarlin, 1993), nos termos do qual a justiça procedimental/ interaccional e a distributiva têm diferentes conseqüências: a procedimental está associada com as avaliações do sistema organizacional (reflectidas em variáveis como a lealdade à organização, o comprometimento organizacional e a confiança na gestão), enquanto a distributiva se associa preferencialmente com a satisfação com os resultados específicos em questão ou os resultados de determinada decisão. Cabe perguntar: o que induz as pessoas a reagirem desse modo quando recebem rosas (a justiça procedimental/interaccional) e não quando recebem o pão (Martin e Harder, 1994)? Várias possibilidades podem ser aventadas, não necessariamente exclusivas.

A primeira pode ser designada de tese instrumental. Presume que as pessoas reagem fundamentalmente em função dos resultados, sendo que os procedimentos e interacções justas as induzem a supor que têm maior probabilidade de obterem resultados mais favoráveis ou justos no futuro (Lind e Tyler, 1988; Cropanzano e Greenberg, 1997). Por conseguinte, não são as rosas, per se, que as induzem a maior comprometimento, mas a expectativa de obterem resultados mais favoráveis e/ou mais justos no futuro. As rosas são, apenas, um sinal revelador de que tal sucederá no futuro.

A segunda noção explicativa assente na tese do valor grupal. Pressupõe que, para que as pessoas reajam positivamente, não é necessário que recebam (ou esperem receber) resultados favoráveis/justos - basta que se sintam dignamente tratadas e valorizadas pelo grupo em que se inserem (Tyler, 1994; Tyler e Degoey, 1995; Tyler, Degoey e Smith, 1996). Essencialmente, a justiça procedimental/ interaccional comunica aos membros do grupo duas mensagens simbólicas. Primeira: se são, ou não, tratados de modo respeitador e positivo; se são ou não considerados “cidadãos de primeira classe” (Organ e Moorman, 1993, p. 13). Segunda: se podem, ou não, ter orgulho pelo facto de pertencerem ao grupo.

A terceira possibilidade interpretativa é a tese do reconhecimento emocional e intelectual: as pessoas respondem positivamente quando se sentem reconhecidas emocional e intelectualmente (Kim e Mauborgne, 1998). O eixo emocional caracteriza-se pelo valor conferido ao indivíduo, não como força de trabalho, membro do pessoal ou recurso humano, mas como ser humano 
que merece ser tratado com dignidade e respeito, e apreciado pelo seu valor individual independentemente do nível hierárquico ou posição que ocupa. O eixo intelectual representa o desejo das pessoas de que as suas ideias sejam solicitadas e acolhidas com reflexão, o direito de contradizer as ideias dos outros, e a vontade de que os outros se dêem ao trabalho de explicarem as próprias ideias. Kim e Mauborgne (1997, p. 69, sem grifo no original) expressaram lapidarmente esta noção ao enunciarem:

“O processo justo responde a uma necessidade humana básica. Todos nós, qualquer que seja o nosso papel na empresa, queremos ser valorizados enquanto seres humanos, e não como 'pessoal' ou 'activos humanos'. Desejamos ser tratados com respeito pela nossa inteligência. Queremos que as nossas ideias sejam tomadas a sério. Gostamos de conhecer as razões que sustentaram decisões específicas. Somos sensíveis aos sinais que são transmitidos pelos processos de tomada de decisão das empresas. Tais processos podem revelar a vontade da empresa em confiar em nós e procurar as nossas ideias - ou assinalar exactamente o contrário".

Importa frisar que na base das três teses está a confiança (Konovsky e Pugh, 1994; Kim e Mauborgne, 1996, 1998; Brockner e Siegel, 1996; Skarlicki e Latham, 1996). Em grande medida, parece ser ela que explica o papel fundamental exercido pela justiça procedimental/interaccional. Quer as pessoas sejam motivadas por razões instrumentais (expectativa de melhores resultados no futuro), quer se movam por razões de identidade grupal e reconhecimento intelectual e emocional, é a confiança nos procedimentos e nos gestores/superiores que as induz a responder positivamente.

Atendendo a que as origens da confiança não se encontram exclusivamente na justiça procedimental e interaccional, é fundamental que os superiores saibam gerar outros mecanismos e actuações que visem a sua promoção. Eis, a título ilustrativo, alguns elementos de presumível importância (Podsakoff et al., 1990, 1996; Mayer e Schoorman, 1995; Brockner e Siegel, 1996; Costa, 1999; Costa, Rose e Taillieu, 1999): o carácter, integridade, lealdade, competência, reputação, boa-fé nas acções, benevolência, consistência de procedimentos, comunicação franca e aberta, discrição (saber manter em segredo o que é confidencial), cumprimento de promessas (explícita ou implicitamente), e adopção de comportamentos de liderança transformacional (por exemplo, articular uma visão; liderar pelo exemplo e servir como modelo de comportamento; encorajar o espírito de equipa; colocar elevadas expectativas nos colaboradores; mostrar respeito e consideração pelos sentimentos das pessoas). 
Note-se que a argumentação antes aduzida contraria a tese económica que assume que as pessoas são maximizadoras da utilidade, conduzidas principalmente por cálculos racionais asssentes no seu auto-interesse. Isto é: focadas apenas nos resultados. Essa premissa migrou para as teorias e práticas da gestão, estando embebida nas ferramentas tradicionalmente usadas para controlar e motivar o comportamento dos empregados, como os sistemas de incentivos e as estruturas organizacionais. Segundo Kim e Mauborgne (1997, p. 65, sem grifo no original), essa assunção tem que ser reexaminada, pois "todos nós sabemos que na vida real as coisas não acontecem sempre desse modo. As pessoas preocupam-se com os resultados mas [...] também com os processos que os produzem. Querem saber que têm uma palavra a dizer, que o seu ponto de vista foi considerado, mesmo que não tenha sido aceite. Os resultados são pertinentes, mas não mais do que os processos que os originam”.

Esta prevalência explicativa da justiça procedimental e interaccional não pode afastar, todavia, algumas considerações atinentes à justiça distributiva. Comecemos pela distribuição de recompensas, tentando compreender o seu nulo poder explicativo do comprometimento. Várias hipóteses explicativas, não necessariamente exclusivas, se afiguram verossímeis:

- Os professores consideram que (já) são beneficiários de um patamar aceitável de justiça recompensatória, pelo que reagem então em função das interacções e dos procedimentos.

- As remunerações dos professores universitários são, pelo menos em diversas áreas, inferiores às vigentes noutras actividades extra-universitárias. As pessoas que optam pela vida universitária fazem-no porque (por razões de personalidade, vocação, valores...) valorizam menos a remuneração e mais outras condições inerentes ao exercício da função.

- As estruturas salariais aplicáveis às instituições públicas (como é o caso das abrangidas pela presente investigação) são determinadas pelo governo central, e não pelas autoridades específicas de cada instituição. Conseqüentemente, numa lógica de reciprocidade, os docentes sentem que a instituição onde exercem funções não merece ser o alvo das suas reacções à (in)justiça recebida/ percepcionada. Esta hipótese explicativa ajuda a lançar luz sobre uma hipótese de trabalho que futuras investigações poderão testar: será que a irrelevância da justiça recompensatória não ocorre nas instituições privadas, pois aí a remuneração tende a estar sob a alçada do governo específico dessa mesma instituição?

Esta última adução erige outras reflexões projectáveis sobre os dados. Note-se que, ao estudarem-se os efeitos interactivos das várias facetas de justiça, se 
descortinou o papel interventor da justiça distributiva das tarefas. Ou seja: as pessoas são especialmente sensíveis a esta faceta distributiva quando as percepções de justiça procedimental ou informacional são fracas (vide Figuras 2 e 3). Esta reacção igualmente tem sentido à luz da teoria da reciprocidade: a distribuição das tarefas (especialmente as pedagógicas e administrativas) depende, em medida muito considerável, da instituição em que o professor exerce funções. Os docentes reagem com mais comprometimento para com a sua instituição porque sentem que esta (e as respectivas autoridades) é responsável por tal distribuição (o que não ocorre com a distribuição recompensatória).

Falta lançar esforços explicativos sobre a interacção das facetas da justiça. Os efeitos encontrados e reflectidos nas Figuras 1-3 são congruentes com os detectados em estudos anteriores (e.g., Cropanzano e Folger, 1991; Brockner e Siegel, 1996; Brockner e Wiesenfeld, 1996; Grienberger, Rutte e Knippenberg, 1997; Skarlicki e Folger, 1997) e sugerem a necessidade de encarar cada faceta não isoladamente, mas em conciliação com as outras. O que parece emergir dessas três configurações pode ser assim traduzido:

. O comprometimento sofre especial erosão quando se conciliam fracas percepções de justiça em duas vertentes.

- As percepções negativas numa faceta reforçam os efeitos negativos oriundos das percepções negativas na outra faceta. As percepções positivas numa faceta reforçam os efeitos positivos oriundos das percepções positivas na outra faceta.

. Quando as pessoas denotam percepções positivas numa das facetas, atenuam as suas reaç̧ões negativas à injustiça na outra faceta.

A evidência que os dados assim permitem extrair apontam para o papel positivo que a justiça distributiva (neste caso das tarefas) pode jogar no comprometimento afectivo dos membros organizacionais. Sublinhe-se, especialmente, o facto de a justiça nesta faceta atenuar os efeitos negativos oriundos de baixa justiça procedimental e informacional. Note-se ainda que, embora a justiça informacional tenha denotado nulo poder preditivo do comprometimento nas análises de regressão, ela assume papel relevante quando é conjugada com a justiça interpessoal e distributiva das tarefas. Em suma: os efeitos interactivos aqui expressos fazem jus aos apelos preconizando a necessidade de não tratar as facetas isoladamente, mas sim em interacção ou conjugação. As reacções dos membros organizacionais são complexas, não se compadecendo com teses simplistas que as tomam como singelas respostas lineares a causas de presumido fácil escrutínio.

Cabe, agora, fazer menção às limitações da pesquisa e desenhar algumas avenidas de investigação futura. O primeiro elemento merecedor de citação 
concerne ao facto de as variáveis dependente (comprometimento) e independente (justiça) terem sido recolhidas na mesma fonte. Este método é susceptível de produzir riscos de variância do método comum (Podsakoff e Organ, 1986; Harrison, Mclaughlin e Coalter, 1996). No caso aqui em apreço, pode suceder que as relações positivas entre justiça e comprometimento se devam ao facto de as (mesmas) pessoas terem respondido aos dois tipos de questões, e não às relações empíricas efectivamente existentes. Uma lógica de pensamento potencialmente perfilhada pelos respondentes pode ter sido assim exposta: "sou tratado com justiça; logo, estou comprometido afectivamente com a minha organização". Daqui decorre a pertinência de pesquisas futuras utilizarem metodologias de dupla fonte, experimentais, ou longitudinais (a obtenção das variáveis dependente e independente produz-se em momentos temporais distintos).

A segunda limitação concerne à natureza correlacional do estudo, não permitindo extrair nexos de causalidade claros. Na verdade, embora seja verossímil que as pessoas reajam às percepções de (in)justiça com mais ou menos comprometimento afectivo, também é intelectualmente viável aduzir que as pessoas mais comprometidas com a sua organização recebem tratamento mais justo da parte dela e respectivos decisores. Pode igualmente haver terceiras variáveis que influenciam simultaneamente as percepções de justiça e o comprometimento, daí advindo a relação estatística entre ambas.

A terceira limitação respeita ao facto de algumas dimensões de justiça não serem claramente independentes de outras. Ilustrativamente, é o que ocorre com as vertentes interaccional e informacional. É certo que a sua autonomização se justifica à luz da análise factorial. Ademais, nas regressões, apenas a faceta interpessoal emerge com poder preditivo. Todavia, não deixa de ser clara a elevada correlação entre as duas variáveis (vide Tabela 3). Futuros estudos poderão contribuir para um esclarecimento empírico-teórico desta temática.

A quarta limitação advém do tratamento exclusivo da vertente afectiva do comprometimento. Embora esta seja a que as pesquisas mais preconizam como promotora do desempenho individual e organizacional, seria mais frutuoso estudála em conjugação com as vertentes normativa e calculativa. Assim se poderia lançar luz adicional sobre o debate acerca da pertinência da tridimensionalização.

Finalmente, posteriores investigações poderão testar os efeitos moderadores de algumas variáveis. Com efeito, não deixaria de ser pertinente saber se as reacções dos professores variam consoante o género, idade, antiguidade, posição na carreira ou tipo de instituição (por exemplo, pública versus privada, universitária versus politécnica). $\mathrm{O}$ facto de os docentes politécnicos serem mais reactivos do que os universitários confere legitimidade à hipótese. 


\section{Conclusões e Implicações para a Gestão das Universidades}

Os dados expostos sugerem que, tal como os membros de outras organizações, os professores do ensino superior são sensíveis ao modo (in)justo como se sentem tratados. Mostram que, contrariamente às presunções segundo as quais as pessoas reagem fundamentalmente à justiça remuneratória, elas respondem à justiça dos procedimentos e das interacções com os superiores. Não é legítimo daqui extrair a ideia de que o pão é irrelevante para os professores universitários - mas é aceitável supor que (pelo menos) eles também respondem às rosas. Os professores desejam que os procedimentos decisórios e promocionais sejam justos, pretendem ser tratados com dignidade e respeito, almejam ser ouvidos nas decisões que lhes dizem respeito, e esperam receber explicações pelas decisões tomadas. $\mathrm{E}$, conseqüentemente, doseiam o comprometimento afectivo que cultivam na relação com a organização onde trabalham.

Esta lógica relembra a tese desenhada por $\operatorname{Kim}$ e Mauborgne $(1997,1998)$ a propósito da relação entre as percepções de justiça e o desempenho individual/ organizacional. Sucintamente, pode ser assim traduzida: (1) a justiça distributiva induz apenas os desempenhos normais; (2) para que os desempenhos ultrapassem as expectativas, é necessário actuar sobre a justiça procedimental/ interaccional, pois é ela que induz a confiança e o comprometimento; (3) há razões para presumir que esta tendência é mais notória com trabalhadores do conhecimento (ou cognitários, para usar uma expressão de Toffler [1991]), como é o caso dos professores.

Do atrás exposto, podem ser apontadas algumas linhas de orientação potencialmente frutuosas para o governo das instituições de ensino superior. Seria precipitado asseverá-las como propostas peremptórias e receituárias. Elas pretendem ser, tão-só, um curto catálogo de ideias, sugestões e reflexões. O conhecimento realista do terreno concreto e as possibilidades reais de actuação que se depararem aos decisores fornecerão o tempero para a sua aplicação ou rejeição:

. É crucial que os decisores tratem com respeito e consideração os docentes, mostrem interesse genuíno em serem justos com eles, respeitem os seus direitos, lidem com eles de modo honesto e ético, actuem de modo franco e sincero com eles.

. É também fundamental que expliquem, discutam e forneçam justificações aos docentes (que foram ou virão a ser) afectados pelas decisões.

- Importa incrementar as possibilidades de participação dos docentes na tomada de decisão, especialmente daqueles que, devido à sua categoria profissional, ficam arredados da pertença a determinados órgãos de decisão e consulta. 
Mesmo que este afastamento seja uma inevitabilidade formal, nada impede que sejam adoptados procedimentos informais de consulta e participação. A qualidade de um número considerável de decisões não está dependente do grau académico ou categoria profissional dos docentes. O nível superior de formação que todos possuem confere-lhes capacidade para intervir, com qualidade, em decisões atinentes a orçamentos, distribuição de serviço docente, alterações de planos de estudos etc.

- Mais: o fornecimento de explicações e informações transmite-lhes um sinal de que são membros respeitados, considerados, e intelectual e emocionalmente válidos. E esse sinal não parece estar inibido pelas estruturas normativas e estatutárias vigentes.

. É crucial que os procedimentos decisórios (nos diversos planos, sejam eles científicos, pedagógicos, profissionais, atinentes a promoções, concessões de apoios financeiros...) assegurem que as decisões são tomadas sem favorecimentos pessoais e de modo consistente ao longo do tempo (embora consistência não signifique imutabilidade).

Em jeito de conclusão, algumas linhas de reflexão são mencionáveis. Primeira: há razões para pensar que os professores mais comprometidos afectivamente nas suas instituições podem contribuir para a melhoria da qualidade no ensino superior. Segunda: as pesquisas empríricas sugerem, com assinalável constância, que os professores mais afectivamente comprometidos e mais praticantes de actos de cidadania são os que percepcionam níveis de justiça mais elevados. Terceira: os dados do presente estudo também apontam nesse sentido, com a particularidade de assinalarem o papel preponderante da justiça interaccional e procedimental. Quarta: daí não pode retirar-se a ilação segundo a qual a justiça distributiva é despicienda.

\section{ReferÊnCIAS Biblográficas}

ADAMS, J. S.

Inequity in social exchange. In: BERKOWITZ, L. (Ed.). Advances in experimental social psychology. New York: Academic Press, 1965. v. 2. p. 267-299.
ALLEN, N. J.;

MEYER, J. P.

The measurement and antecedents of affective, continuance, and normative commitments to the organization. Journal of Occupational Psychology, v. 63, p.1-8, 1990. 
Affective, continuance, and normative commitment to the organization: an examination of construct validity. Journal of Vocational Behavior, v. 49, p. 252-276, 1996.

\section{BAGRAIM, J.}

Understanding the organizational commitment of knowledge workers. In: INTERNATIONAL CONGRESS OF PSYCHOLOGY, 27., 2000, Stockholm). Proceedings... Stockholm: [s.n.], 2000.

\section{BAILEY, D.;}

\section{BENNETT, J. V.}

The realistic model of higher education. Quality Progress, p. 77-79, Nov. 1996.

BECKER, T. E.

Foci and bases of commitment: are they distinctions worth making? Academy of Management Journal, v. 35, n. 1, p. 232-244, 1992.

BIES, R. J. ; MOAG, J. S.

Interactional justice: communication criteria of fairness. In: LEWICKI, R. J.; SHEPPARD, B. H.; BAZERMAN, M. H. (Eds.). Research on negotiation in organizations. Greenwich, CT: JAI Press, 1986. v. 1. p. 43-55.
BLAU, P. M.

Exchange and power in social life. New Brunswick, NJ: Transaction Publishers, 1964.

BLOOM, M.

The performance effects of pay dispersions on individuals and organizations. Academy of Management Journal, v. 42, n. 1, p. 25-40, 1999.

BOLON, D. S.

Organizational citizenship behavior among hospital employees: a multidimensional analysis involving job satisfaction and organizational commitment. Hospital \& Health Services Administration, v. 42, n. 2, p. 221-241, 1997.

BROCKNER, J.; SIEGEL, P.

Understanding the interaction between procedural and distributive justice: the role of trust. In: KRAMER, R. M.; TYLER, T. R. (Eds.). Trust in organizations: frontiers of theory and research. London: Sage Publications, 1996. p. 390-413.

BROCKNER, J.;

WIESENFELD, B. M.

An integrative framework for explaining reactions to decisions: interactive effects of outcomes and procedures. Psychological Bulletin, v. 120, n. 2, p. 189-208, 1996. 
BYRNE, B. M.

Structural equation modeling with Lisrel, Prelis, and Simplis. London: Lawrence Erlbaum, 1998.

CAETANO, A.;

VALA, J.

Efeitos da justiça organizacional percebida sobre a satisfação no trabalho e as opções comportamentais. Psicologia, v. XIII, n. 1-2, p. 75-84, 1999.

\section{COHEN, A.}

The relationship between commitment forms and work outcomes: a comparison of three models. Human Relations, v. 53, n. 3, p. 387-417, 2000.

COsTA, A. C.

Theoretical considerations over trust: relevant aspects for organizational behavior. Psicologia, v. XIII, n. 1-2, p. 8598, 1999.

COSTA, A. C.;

ROE, R. A. ;

TAILLIEU, T.

Trust within teams: implications for performance and effectiveness. In: EUROPEAN CONGRESS OF EUROPEAN ASSOCIATION ON WORK AND ORGANIZATIONAL PSYCHOLOGY, 9., 1999, Helsinki. Proceedings... Helsinki: [s.n.], 1999.
CROPANZANO, R.;

FOLGER, R.

Procedural justice and worker motivation. In: STEERS, R. M.; POTER, L. W. (Eds.). Motivation and work behavior. 5. ed. New York: McGraw-Hill, 1991. p. 131-143.

CROPANZANO, R.;

GREENBERG, J.

Progress in organizational justice: tunneling through the maze. In: COOPER, C. L.; ROBERTSON, I. T. (Eds.). International review of industrial and organizational psychology. New York: John Wiley \& Sons, 1997. v. 12. p. 317-372.

ELLINGTON, H.;

ROSS, G.

Evaluating teaching quality throughout a university. Quality Assurance in Education, v. 2, n. 2, p. 4-9, 1994.

FEIGENBAUM, A. V.

Quality education and America's competitiveness. Quality Progress, p. 83-84, Sept. 1994.

FINEGAN, J. E.

The impact of person and organizational values on organizational commitment. Journal of Occupational and Organizational Psychology, v. 73, p. 149-169, 2000. 
FOLGER, R.;

KONOVSKY, M. A.

Effects of procedural and distributive justice on reactions to pay raise decisions. Academy of Management Review, v. 32, n. 1, p. 115-130, 1989.

GOLEMAN, D.

Trabalhar com inteligência emocional. Lisboa: Temas \& Debates, 1998.

GOULDNER, A. W.

The norm of reciprocity: a preliminary statement. American Sociological Review, v. 25, p. 161-178, 1960.

\section{GREENBERG, J.}

Organizational justice: yesterday, today and tomorrow. Journal of Management, v. 16, n. 399-432, 1990.

The social side of fairness: interpersonal and informational classes of organizational justice. In: CROPANZANO, R. (Ed.). Justice in the workplace: approaching fairness in human resource management. Hillsdale, NJ: Erlbaum, 1993a. p. 79-103.

The intellectual adolescence of organizational justice: you've come a long way, maybe. Social Justice Research, v. 6, n. 1, p. 135-148, 1993b.
GREENBERG, J.;

MCCARTY, C. L.

The interpersonal aspects of procedural justice: a new perspective on pay fairness. Labor Law Journal, v. 41, p. 580-586, 1990.

GRIENBERGER, I. V.;

RUTTE, C. G.;

KNIPPENBERG, A. F. M.

Influence of social comparisons of outcomes and procedures on fairness judgments. Journal of Applied Psychology, v. 82, n. 6, p. 913-919, 1997.

HACKETT, R. D.;

BYCIO, P.;

HAUSDORF, P. A.

Further assessments of Meyer and Allen's (1991) threecomponent model of organizational commitment. Journal of Applied Psychology, v. 79, p. 15-23, 1994.

HANSEN, W. L.;

JACKSON, M.

Total quality improvement in the classroom. Quality in Higher Education, v. 2, n. 3, p. 211-217, 1996.

HARRISON, D. A.;

MCLAUGHLIN, M. E.;

COALTER, T. M.

Context, cognition, and common method variance: psychometric and verbal protocol evidence. Organizational Behavior and Human Decision Processes, v. 68, n. 3, p. 246-261, 1996. 
HARTMAN, S. J.;

YRLE, A. C.;

GALLE JR, W. P. G.

Equity in a university setting: examining procedural and distributive justice. International Journal of Management, v. 15, n. 1, p. 3-13, 1998.

HELMS, S.;

KEY, C. H.

Are students more than costumers in the classroom? Quality Progress, p. 97-99, Sept. 1994.

HORSBURGH, M.

Quality monitoring in higher education: the impact on student learning. Quality in Higher Education, v. 5, n. 1, p. 9-25, 1999.

IVERSON, R. D.

Employee acceptance of organizational change: the role of organizational commitment. The International Journal of Human Resource

Management, v. 7, n. 1, p. 1523, 1996.

IVERSON, R. D.;

BUTTIGIEG, D. M.

Affective, normative and continuance commitment: can the 'right kind' of commitment be managed? Journal of Management Studies, v. 36, n. 3, p. 307-333, 1999.
JORESKOG, K.;

SORBOM, D.

Lisrel 8: structural equation modeling with the simples command language. [S.l.]: Scientific Software International, 1993.

KIM, W. C.;

MAUBORGNE, R.

Implementing global strategies: the role of procedural justice. Strategic Management Journal, v. 12, p. 125-143, 1991.

Procedural justice and managers' in-role and extra-role behavior: the case of the multinational. Management Science, p. 499515, Apr. 1996.

Fair process: managing in the knowledge economy. Harvard Business Review, v. 75, n. 4, p. 65-75, 1997.

Procedural justice, strategic decision making and the knowledge economy. Strategic Management Journal, v. 19, p. 323-338, 1998.

KONOVSKY, M. A.

Understanding procedural justice and its impacts on business organizations. Journal of Management, v. 26, n. 3, p. 489511, 2000. 
KONOVSKY, M. A.;

CROPANZANO, R.

Perceived fairness of employee drug testing as a predictor of employee attitudes and job performance. Journal of Applied Psychology, v. 76, p. 698-707, 1991.

KONOVSKY, M. A.;

PUGH, S. D.

Citizenship behavior and social exchange. Academy of Management Journal, v. 37, n. 3, p. 656-669, 1994.

LEE, C.;

FARH, J.

The effects of gender in organizational justice perception. Journal of Organizational Behavior, v. 20, p. 133-143, 1999.

LIND, E. A.;

TYLER, T. R.

The social psychology of procedural justice. New York: Plenum, 1988.

MACKENZIE, S. B.; PODSAKOFF, P. M.;

AHEARNE, $M$.

Some possible antecedents and consequences of in-role and extra-role salesperson performance. Journal of Marketing, v. 62, p. 87-98, July 1998.
MARTIN, J.;

HARDER, J. W.

Bread and roses: justice and the distribution of financial and socioemotional rewards in organizations. Social Justice Research, v. 7, n. 3, p. 241-264, 1994.

MAYER, R. C.;

SCHOORMAN, F. D.

An integrative model of organizational trust. Academy of Management Review, v. 20, n. 3, p. 709-734, 1995.

MCFARLIN, D. B.;

SWEENEY, P. D.

Distributive and procedural justice as predictors of satisfaction with personal and organizational outcomes. Academy of Management Journal, v. 35, n. 3, p. 626-637, 1992.

MCGEE, G. W.; FORD, R. C.

Two (or more?) dimensions of organizational commitment: reexamination of the affective and continuance commitment scales. Journal of Applied Psychology, v. 72, p. 638-641, 1987.

MEYER, J. P.

Organizational commitment. In: COOPER, C. L.; ROBERTSON, I. T. (Eds.). International review of industrial and organizational psychology. New York: John Wiley \& Sons, 1997. v. 12. p. 175-228. 
MEYER, J. P.;

ALLEN, N. J.

Testing the "side-bet theory" of organizational commitment: some methodological considerations. Journal of Applied Psychology, v. 69, p. 372-3768, 1984.

A three-component conceptualization of organization commitment. Human Resource Management Review, v. 1, p. 61-98, 1991.

MEYER, J. P. et al.

Organizational commitment and job performance: it's nature of the commitment that counts. Journal of Applied Psychology, v. 74, p. 152-156, 1989.

MONTANO, C. B.;

UTTER, G. H.

Total quality management in higher education. Quality Progress, p. 52-59, Aug. 1999.

MOORMAN, R. H.;

NIEHOFF, B. P.;

ORGAN, D. W.

Treating employees fairly and organizational citizenship behavior: sorting the effects of job satisfaction, organizational commitment, and procedural justice.

Employee Responsibilities and Rights Journal, v. 6, n. 3, p. 209-225, 1993.
MOSSHOLDER, K. W.;

KEMERY, E. R.;

WESOLOWSKI, M. A.

Relationships between bases of power and work reactions: the mediational role of procedural justice. Journal of Management, v. 24, n. 4, p. 533552, 1998.

MOWDAY, R. T.;

STEERS, R. M.

The measurement of organizational commitment. Journal of Vocational Behavior, v. 14, p. 224-247, 1979.

NAUMANN, S. E. et al.

Laid off, but still loyal: the influence of perceived justice and organizational support. The International Journal of Conflict Management, v. 9, n. 4, p. 356-368, 1998.

NUNNALLY, J. C.

Psychometric theory. 2. ed. New York: McGraw-Hill, 1978.

O’ REILLY, C.;

CHATMAN, J.

Organizational commitment and psychological attachment: the effects of compliance, identification, and internalization on prosocial behavior. Journal of Applied Psychology, v. 71, n. 3, p. 492-499, 1986. 
ORGAN, D. W.;

MOORMAN, R. H.

Fairness and organizational citizenship behavior: what are the connections? Social Justice

Research, v. 6, n. 1, p. 5-18, 1993.

PAVULS, U.

Exploratory factor analysis of organizational commitment in Eastern Europe. In: INTERNATIONAL CONGRESS OF PSYCHOLOGY, 27., 2000, Stockholm). Proceedings... Stockholm: [s.n.], 2000.

PODSAKOFF, P. M. et al.

Transformational leader behaviors and their effects on followers' trust in leader, satisfaction, and organizational citizenship behavior. Leadership Quarterly, v. 1, p. 107-142, 1990.

PODSAKOFF, P. M.;

ORGAN, D. W.

Self-reports in organizational research: problems and prospects.

Journal of Management, v. 12, p. 531- 544, 1986.

POND III, S. B. et al.

The measurement of organizational citizenship behavior: are we assuming too much? Journal of Applied Social Psychology, v. 27, p. 1527-1544, 1997.
PORTER, L. W.;

STEERS, R. M.;

MOWDAY, R. T.

Organizational commitment, job satisfaction, and turnover among psychiatric technicians. Journal of Applied Psychology, v. 59, n. 5, p. 603-609, 1974.

RAWLS, J.

A theory of justice. Cambridge, MA: Harvard University Press, 1971.

REGO, A.

Cidadania docente universitária: sua relação com o desempenho dos estudantes. Revista Portuguesa de Educação, v. 13, n. 2, p. 199-217, 2000a.

Cidadania docente universitária a perspectiva dos diplomados. Revista Brasileira de Estudos Pedagógicos, 2000b. No prelo.

O bom cidadão docente universitário - na senda da qualidade no ensino superior. Educação \& Sociedade, 2000c. No prelo.

Justiça e cidadania nas organizações - uma abordagem sem tabus. Lisboa: Edições Silabo, 2000d. 
Justiça organizacional - na senda de uma nova vaga? In: RODRIGUES, S. B.; CUNHA, M. P. (Orgs.). Estudos organizacionais: novas perspectivas na administração de empresas - uma coletânea luso-brasileira. São Paulo: Iglu, 2000e. p. 251-283.

\section{Comportamentos de cidadania organizacional - uma abordagem empírica a alguns dos seus antecedentes e conseqüências. Lisboa, 2000f. Tese (Doutorado) - Instituto Superior de Ciências do Trabalho e da Empresa.}

Justiça organizacional: desenvolvimento e validação de um instrumento de medida. Psicologia, v. XIV, n. 2, p. 285307, 2000g.

Percepções de justiça dos professores do ensino superior desenvolvimento e validação de um instrumento de medida. Linhas Críticas, 2001a. No prelo.

Percepções de justiça dos professores do ensino superior um estudo confirmatório. Psicologia, 2001b. No prelo.

REGO, A.;

REIS, D.

Concepções dos ex-alunos acerca da cidadania docente universitária - uma perspectiva luso-brasileira.
Tecnologia e Humanismo, 2001. No prelo.

REGO, A.;

SOUSA, L.

Impactos dos comportamentos de cidadania docente sobre os alunos universitários - a perspectiva dos estudantes e dos professores. Linhas Críticas, v. 6, n. 10, p. 930, 2000.

\section{ROWLEY, J.}

Measuring quality in higher education. Quality in Higher Education, v. 2, n. 3, p. 237-255, 1996.

\section{RUBACH, L.}

Transforming U. S. education with the quality movement. Quality Progress, p. 93-95, Sept. 1994.

SALLIS, E.

Total quality management in education. London: Kogan Page, 1993.

SCHARGEL, F. P.

Teaching TQM in a inner city high school. Quality Progress, p. 8790, Sept. 1994.

SCHAUBROECK, J.;

MAY, D. R.;

BROWN, F. W.

Procedural justice explanations and employee reactions to economic hardship: a field experiment. Journal of Applied Psychology, v. 79, n. 3, p. 455460, 1994. 
SKARLICKI, D. P.;

FOLGER, R.

Retaliation in the workplace: the roles of distributive, procedural, and interactional justice. Journal of Applied Psychology, v. 82, n. 3, p. 434-443, 1997.

SKARLICKI, D. P.;

LATHAM, G. P.

Increasing citizenship behavior within a labor union: a test of organizational justice theory. Journal of Applied Psychology, v. 81, n. 2, p. 161-169, 1996.

\section{SWAILES, S.}

Organizational commitment: searching for the Holy Grail of HRM. Comportamento Organizacional e Gestão, v. 6, n. 2, p. 199-212, 2000.

SWEENEY, P. D.;

MCFARLIN, D. B.

Workers' evaluations of the 'ends' and the 'means': an examination of four models of distributive and procedural justice. Organizational Behavior and Human Decision Processes, v. 55, p. 23-40, 1993.

Process and outcome: gender differences in the assessment of justice.

Journal of Organizational Behavior, v. 18, p. 83-98, 1997.
TANSKY, J. W.

Justice and organizational citizenship behavior: what is the relationship? Employee Responsibilities and Rights Journal, v. 6, n. 3, p. 195-207, 1993.

THIBAUT, J.;

WALKER, J.

Procedural justice: a psychological analysis. Hillsdale, NJ: Erlbaum, 1975.

A theory of procedure. California Law Review, v. 66, p. 541-566, 1978.

TOFFLER, A.

Os novos poderes. Lisboa: Livros do Brasil, 1991.

TYLER, T. R.

Psychological models of the justice motive: antecedents of distributive and procedural justice. Journal of Personality and Social Psychology, v. 67, n. 5, p. 850863, 1994.

TYLER, T. R.;

BIES, R. J.

Beyond formal procedures: the interpersonal context of procedural justice. In: CARROLL, J. S. (Ed.). Applied social psychology in business settings. Hillsdale, NJ: Erlbaum, 1990. p. 77-98. 
TYLER, T. R.;

DEGOEY, P.

Collective restraint in social dilemmas: procedural justice and social identification effects on support for authorities. Journal of Personality and Social Psychology, v. 69, n. 3, p. 482497, 1995.

TYLER, T. R.;

DEGOEY, P.;

SMITH, $\mathrm{H}$.

Understanding why the justice of group procedures matters: a test of the psychological dynamics of the group-value model. Journal of Personality and Social Psychology, v. 70, n. 5, p. 913930, 1996.

WILLIAMS, S.

The effects of distributive and procedural justice on performance. The Journal of Psychology, v. 133, n. 2, p. 183193, 1999.
YORKE, M.

This way QA? Quality Assurance in Education, v. 5, n. 2, p. 97-100, 1997.

\section{YOUSEF, D. A.}

Organizational commitment: a mediator of the relationships of leadership behavior with job satisfaction and performance in a non-western country. Journal of Managerial Psychology, v. 15, n. 1, p. 6-28, 2000a.

Organizational commitment as mediator of the relationship between Islamic work ethic and attitudes toward organizational change. Human Relations, v. 53, n. 4, p. 513-537, 2000b. 